\title{
A PROVA DA EXISTÊNCIA DA MULTIPLICIDADE DE CORPOS NA SEXTA MEDITAÇÃO
}

César Augusto Battisti*

\section{RESUMO}

Este artigo analisa a prova da existência dos corpos apresentada por Descartes na Sexta Meditação e defende a tese de que - se bem sucedida em outros aspectos nele não examinados - ela necessariamente prova a existência de uma multiplicidade de entidades materiais. Este texto nos convoca, portanto, a interpretar literalmente a conclusão da prova, quando ela afirma que "coisas corporais existem" (no plural). O argumento central pode ser assim sintetizado: 1) se há ideias sensíveis distintas é porque a mente se submete a coações distintas, em razão dos modos distintos pelos quais o poder causal é exercido; 2) embora tais modos distintos de exercício causal não requeiram múltiplas causas, a natureza formal da causa o exige: a individuação de cada ideia-efeito requer a individuação de cada entidade-causa.

Palavras-chave: Descartes. Existência dos corpos. Multiplicidade de corpos. Ideias sensíveis. Causa formal.

\section{RÉSUMÉ}

Cet article analyse la preuve de l'existence des corps, présentée par Descartes dans la Sixième Méditation, et soutient la thèse selon laquelle - si la preuve est bien faite en d'autres aspects ici non examinés - elle prouve nécessairement l'existence d'une multiplicité d'entités

\footnotetext{
* Professor dos cursos de graduação e de mestrado em Filosofia da Universidade Estadual do Oeste do Paraná (Unioeste).E-mail: cesar.battisti@hotmail.com
} 
matérielles. L'article nous conduit donc à interpréter littéralement sa conclusion, quand elle affirme que "des choses corporelles existent" (au pluriel). L'argument central peut être ainsi synthétisé: 1) s'il y a des idées sensibles distinctes c'est parce que l'esprit se soumet à des contraintes distinctes, dues aux façons distinctes par lesquelles le pouvoir causal est exercé; 2) même si ces façons distinctes d'exercice causal ne requièrent pas de causes multiples, la nature formelle de la cause l'exige: 1' individuation de chaque idée-effet requiert l'individuation de chaque entité-cause.

Mots clé: Descartes. Existence des corps. Multiplicité des corps. Idées sensibles. Cause formelle.

I. O objetivo do presente texto consiste em examinar a prova da existência dos corpos apresentada por Descartes na Sexta Meditação (parágrafos 19 e 20, segundo algumas edições), ${ }^{1}$ tendo como ponto gravitacional a sua conclusão, na medida em que esta implica (ou parece implicar) não só a existência, mas também a pluralidade de coisas materiais. ${ }^{2}$ Com efeito, a conclusão afirma, literalmente, tanto em latim quanto em francês, que "coisas corporais existem", 3 o que nos permite considerar que a prova determina tanto a existência quanto a

\footnotetext{
${ }^{1}$ As citações de Descartes serão feitas a partir da edição standard das suas obras completas (Euvres de Descartes), editadas por Charles Adam e Paul Tannery (AT). Embora essa edição não enumere os parágrafos das Meditações, outras edições o fazem, dentre as quais várias traduções brasileiras (por exemplo, DESCARTES, 1983; 2000; 2004).

${ }^{2}$ Poder-se-ia questionar esse ponto de vista de que a prova se resuma ao texto que será aqui examinado. Embora o problema da existência dos corpos seja muito complexo e tenha se originado no início do percurso meditativo, parece-me que, mesmo assim, podemos localizar a prova propriamente dita dentro dos limites propostos, como procedem também Gueroult (1953, II, p. 76-83) e Landim Filho (1997, p. 152-156; 1992, p. 70-72), dentre outros.

${ }^{3}$ Diz Descartes nos originais latino e francês: "Ac proinde res corporeae existunt" (AT VII, p. 80); "Et partant il faut confesser qu'il y a des choses corporelles qui existent” (AT IX, p. 63).
} 
multiplicidade de entidades ou, melhor ainda, que ela determina a existência concomitante de uma multiplicidade de entidades.

Ora, visto que, em princípio, é possível a um juízo de existência apontar a realidade, seja de apenas uma única entidade, seja de múltiplas entidades, ${ }^{4}$ podemos nos perguntar pelas razões e pelas circunstâncias que conduziram o filósofo, se esse for o caso, à conclusão a respeito da pluralidade material: em todo juízo de existência, dentro da perspectiva cartesiana, a posição de existência parece não poder ser dissociada do posicionamento relativo à identificação da(s) entidade(s) existente(s) e, portanto, também do posicionamento relativo à sua individuação e à sua determinação numérica, de modo que deve haver, em cada juízo, algum elemento pelo qual se dê a escolha entre as alternativas quanto a esse último aspecto. Ademais, tendo em conta que a "ontologia do mundo material" cartesiana concebe apenas uma única res extensa, homogênea e indeterminada, a tese de que essa res extensa seja detectada pela mente concomitantemente à admissão de sua diferenciação interna ou divisibilidade efetiva (de onde advém a multiplicidade dos corpos) deve merecer a devida consideração.

Dentro desse quadro teórico pretendo defender as seguintes afirmações: a) que, efetivamente, devemos assumir o sentido literal da conclusão "coisas corporais existem" e que, portanto, a prova da existência é a prova da existência de múltiplos corpos; b) que a tese da multiplicidade não pode ter sido introduzida nem anteriormente nem posteriormente à prova, mas no interior dela; c) que deve haver um critério constitutivo da prova que tenha permitido a derivação da tese da multiplicidade conjuntamente à conclusão da tese da existência.

Começaremos com uma exposição da prova antes do exame do problema propriamente dito.

\footnotetext{
${ }^{4}$ Veremos, mais adiante, exemplos de juízos que determinam a existência de apenas uma entidade.
} 
II. A prova da existência dos corpos da Sexta Meditação, ainda que bastante breve em sua forma de apresentação, comporta diferentes etapas, todas elas bem articuladas dentro do melhor estilo cartesiano de meditar. ${ }^{5}$ Segue o texto na íntegra:

Agora, há na verdade em mim uma certa faculdade passiva de sentir ou de receber e conhecer idéias das coisas sensíveis, a qual me seria, no entanto, totalmente inútil, se não existisse também, em mim ou em outra coisa, uma certa outra faculdade ativa, que produza ou cause essas idéias.

Mas é seguro que essa faculdade ativa não pode estar em mim, enquanto não sou senão uma coisa pensante. Porque, de um lado, não pressupõe nenhuma intelecção e, de outro lado, essas idéias produzem-se sem a minha cooperação e, com freqüência, até contrariando minha vontade.

Resta, pois, que esteja numa substância diversa de mim, na qual deve estar contida formal ou eminentemente (como já fiz notar) toda a realidade que está contida objetivamente nas idéias produzidas por essa faculdade. Essa substância ou é um corpo, uma natureza corporal - na qual está contido formal e efetivamente tudo o que está contido nas idéias objetivamente e por representação-, ou é por certo Deus ou alguma criatura mais nobre que o corpo - na qual está contido eminentemente.

Mas, como não é enganador, é de todo manifesto que Deus não põe por si, imediatamente, essas idéias em mim, nem mediante alguma criatura que contivesse não formalmente, mas só eminentemente, a realidade que, nelas, é objetiva.

Pois, como ele não me deu nenhuma faculdade para o reconhecer e, ao contrário, deu-me uma grande propensão a crer que elas são emitidas das coisas corporais, não vejo razão por que não o possa entender enganador, se essas idéias forem emitidas de alhures que

\footnotetext{
${ }^{5}$ São dois os textos em que Descartes apresenta uma prova da existência dos corpos. O segundo são os Princípios, II, Art. 1 (AT VIII, p. 40-41; IX-2, p. 63-64). Para os objetivos do presente estudo, restringir-me-ei à prova apresentada nas Meditações.
} 
não das coisas corporais.

Por conseguinte, é preciso confessar que as coisas corporais existem (AT VII, p. 79-80; IX-1, p. 63). ${ }^{6}$

Seguindo de perto a exposição feita por Landim Filho e a análise minuciosa oferecida por Gueroult, apresentarei a prova em vários passos, incluindo aí, diferentemente deles, também a conclusão, ${ }^{7}$ mas sem que haja discordâncias fundamentais no que diz respeito aos seus elementos, havendo apenas diferenças na forma de aglutiná-los ou de separá-los. Tendo como ponto de partida o fato indubitável da existência, na mente, da capacidade de sentir ou de ter ideias sensíveis, a prova apresenta as seguintes seis etapas, cada qual correspondendo a um parágrafo da citação (com inversão entre os passos 4 e 5): 1) há uma faculdade ativa correspondente à minha capacidade passiva de sentir; 2) essa faculdade ativa não pode existir em mim e, portanto, é exterior e independente em

${ }^{6}$ Para as Meditações, utilizarei a tradução de Fausto Castilho (DESCARTES, 2004), feita a partir do texto latino e com incorporação (em itálico) das modificações do texto em língua francesa. Na atual citação, a divisão em parágrafos é do tradutor, com exceção da última, que introduzi para pôr a conclusão em destaque. Não há correspondência na divisão dos parágrafos entre a tradução e os originais (entre si também discordantes). As demais traduções foram feitas por mim.

${ }^{7}$ Martial Gueroult (1953, II, p. 77-83) secciona a prova em oito etapas. São as seguintes: i) a passividade própria do sentir, um modo do pensamento; ii) implicação recíproca entre ação e paixão; iii) o caráter não mental da faculdade produtiva das ideias sensíveis; iv) o constrangimento em mim, próprio à passividade do sentir; v) atuação do princípio de causalidade; vi) presença de uma inclinação natural a crer que os corpos causam as sensações; vii) apelo à veracidade divina; viii) a incorrigibilidade da crença natural. Por sua vez, Landim Filho (1997, p. 152-156) separa a prova nas seguintes quatro etapas: a) existe um princípio ativo correspondente à passividade das sensações; b) esse princípio é exterior e independente em relação à mente; c) os corpos, sendo exteriores ao sujeito pensante, podem ser a causa da passividade das sensações na consciência; d) há uma inclinação natural e incorrigível a crer que são as coisas corporais que nos enviam as ideias sensíveis, de modo que Deus seria enganador se esse princípio ativo não fosse identificado com os corpos. Em outro texto, o autor a apresenta em três etapas (LANDIM FILHO, 1992, p. 70-72). Sobre vários aspectos da prova, vale a pena consultar também Schirmer (2003). 
relação à mente; 3) tal faculdade deve residir em uma substância na qual esteja contida formalmente ou eminentemente toda a realidade objetiva das ideias produzidas por essa faculdade; 4) há uma inclinação natural e incorrigível a crer que são os corpos que me enviam tais ideias; 5) Deus seria enganador se as ideias sensíveis não fossem enviadas pelas coisas corporais; 6) portanto, sendo a causa das ideias sensíveis, conclui-se que os corpos existem. ${ }^{8}$

Exposta a prova esquematicamente, segue a exposição de cada passo.

1) Há uma faculdade ativa correspondente à minha capacidade passiva de sentir. Descartes inicia a prova com a constatação de que há na mente um modo de pensar, que é o sentir, do qual o sujeito é imediatamente consciente, tal como de todo outro modo de pensar. ${ }^{9}$ Essa consciência sensível, entretanto, caracteriza-se pela passividade: ela é a consciência de uma passividade e de uma receptividade em razão do caráter involuntário da manifestação desse gênero de ideias. Estabelecido esse fato, o autor recorre ao princípio da correlação entre passividade e atividade: se a consciência sensível é a consciência de uma passividade,

\footnotetext{
${ }^{8}$ Essa é a prova da existência dos corpos, no sentido estrito do termo. A resolução do problema da existência dos corpos, entretanto, em seu sentido mais amplo, envolve a Quinta e a Sexta Meditação. Reconhece a Quinta Meditação: “Agora, nada parece mais urgente [...] de que me esforce por safar-me das dúvidas em que caí nos últimos dias e veja se pode haver algo certo no que se refere às coisas materiais" (AT VII, p. 63; IX-1, p. 50). Por sua vez, a Sexta Meditação elege como seu problema central o da existência das coisas materiais. Pelo menos assim afirma sua primeira frase: "Resta-me examinar se as coisas materiais existem" (AT VII, p. 71; IX-1, p. 57).

${ }^{9}$ A prova se deve ao exame de um tipo de ideias, as sensíveis. As ideias claras e distintas das coisas materiais, de natureza intelectual, mostraram a possibilidade da existência dos corpos, como decorrência imediata da reabilitação das verdades matemáticas. Por sua vez, as ideias imaginativas denunciam a sua probabilidade, em razão basicamente do fato de não pertencerem à essência do espírito e de se voltarem para fora dele, isto é, para o corpo, o que as torna mais restritas e exigem do sujeito "certa peculiar contenção do ânimo" (AT VII, p. 72; IX-1, p. 58).
} 
sendo atividade e passividade aspectos de um mesmo evento, é preciso que haja uma faculdade ativa correspondente. ${ }^{10} \mathrm{~A}$ consciência sensível denuncia também uma coação e, portanto, uma presença, uma vez que a coação independe do consentimento do sujeito pensante. As consciências da receptividade e da coação, entretanto, não pressupõem uma causa externa à mente: elas podem ser produzidas por uma faculdade oculta pertencente ao próprio sujeito.

2) Essa faculdade ativa não pode existir em mim e, portanto, é exterior e independente em relação à mente. A segunda etapa elimina a possibilidade de a faculdade ativa residir na mente, em razão dos resultados da prova da distinção real entre mente e corpo. Dessa tese resulta a conclusão de que a essência da alma, enquanto sujeito pensante, é pensar. Como pensar é estar consciente, o sujeito pensante conhece todos seus atos e faculdades. Sendo transparente a si mesmo, ele tem consciência de tudo o que nele ocorre. ${ }^{11}$ Logo, não pode haver no sujeito pensante uma faculdade de produzir pensamentos que lhe seja desconhecida. ${ }^{12}$ Disso se segue que a causa do sentimento de passividade

\footnotetext{
${ }^{10}$ Sobre essas noções e seu aspecto relacional, cf. a Carta ao Hyperaspistes, de agosto de 1641 (AT III, p. 428; Alquié II, p. 366) e as Paixões da alma, I, Art. 1 (AT XI, p. 326-27).

${ }^{11}$ Diz Descartes na Carta a Mersenne, de 31 de dezembro de 1640: “... que nihil potest esse in me, hoc est in mente, cujus non sim conscius, provei-o nas Meditações, e se segue disto que a alma é distinta do corpo, e que sua essência é pensar" (AT III, p. 273).

${ }^{12}$ A prova da distinção opera uma oposição total e definitiva entre a res cogitans e a res extensa, cuja consequência é a incomensurabilidade completa entre ambas. Ela efetua, primeiramente, uma distinção entre essências, entre a alma, uma coisa pensante e inextensa, e o corpo, algo extenso e não pensante. Ela efetua também a distinção entre os dois conjuntos de atributos referentes a cada uma das substâncias. Tais atributos, na medida em que pertencem ou se referem a uma delas, são igualmente incomensuráveis em relação aos da outra, não havendo, portanto, nada de comum ou intercambiável, mesmo do ponto de vista modal, entre a res cogitans e a res extensa. E, assim, a alma em nada partilha com o corpo, se este existir. E, autotransparente, nada esconde para si mesma.
} 
e de coerção da consciência sensível não pode residir no sujeito pensante, mas em algo diferente dele e exterior a ele. Há algo exterior à consciência, que é a causa desses sentimentos.

3) Tal faculdade deve residir em uma substância na qual toda a realidade objetiva das ideias produzidas por essa faculdade esteja contida formalmente ou eminentemente. Essa terceira etapa permite apontar os candidatos a serem causas das ideias sensíveis, causas que devem ser exteriores e distintas do sujeito pensante. Se for uma causa eminente, poderá ser Deus ou outra criatura que tenha mais graus de realidade do exigido pelas ideias sensíveis. Se for uma causa formal, será o próprio corpo e corresponderá em graus de realidade ao exigido pelas ideias. Já se sabe, desde a Terceira Meditação, que Deus é exterior e independente da mente; pela distinção real se soube que as coisas extensas, por serem realmente distintas, podem existir independentemente, não tendo suas propriedades nada de comum com as da mente. Portanto, as coisas corporais seriam exteriores em dois sentidos, como diz Landim Filho (1997, p. 155): teriam uma existência independente do sujeito e seriam realidades espaciais. É aqui apenas que aparece o princípio de causalidade, embora a noção de causa apareça ao longo de toda a prova. Ele não é utilizado, entretanto, em razão do grau indeterminado de realidade objetiva das ideias sensíveis, para demonstrar a existência dos corpos, mas para indicar as possíveis causas e a proporção de graus de perfeição entre ideia e coisa em cada caso. Relembrando que deve haver na causa ao menos tanta realidade quanto no efeito, podendo, entretanto, exceder, a causa pode ser eminente ou formal.

4) Há uma inclinação natural e incorrigivel a crer que são os corpos que me enviam tais ideias. Nessa quarta etapa, Descartes denuncia a presença de uma inclinação natural incorrigível que nos conduz a crer que os corpos são a causa formal das ideias sensíveis. Essa inclinação é, por um lado, natural, nascida do meu ser. Por outro, é incorrigível, dada a ausência de qualquer faculdade corretiva. ${ }^{13}$ Tal como acontece

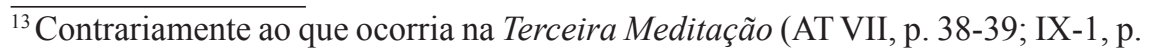


com as ideias claras e distintas que, verdadeiras em razão da regra da evidência, se apoiam em uma "regra da inclinação sem correção", de sorte que estamos seguros de não haver imperfeição positiva alguma na faculdade de julgar, uma vez que não existe outra que possa corrigi-la, ${ }^{14}$ as ideias sensíveis são incorrigíveis de modo semelhante: inclinamo-nos irresistivelmente a crer que os corpos são causa das ideias sensíveis, não havendo faculdade alguma que pretenda indicar sua falsidade. A diferença entre os dois casos é fundamentalmente o fato de que, em um, trata-se de ideias claras e distintas e, no outro, de uma crença obscura e confusa. Contudo, em ambas há uma propensão (racional ou instintiva) e ambas são incorrigíveis.

5) Deus seria enganador se as ideias sensiveis não fossem enviadas pelas coisas corporais. Essa etapa coroa a anterior ao apontar que Deus, ser veraz e não enganador, criador de tudo (e, portanto, de minha natureza), ratifica a inclinação natural; em razão de sua incorrigibilidade: a ausência de um meio que viesse a corrigir a inclinação natural é garantia da sua verdade, uma vez que o Criador não constituiu o ser pensante de tal modo que pudesse infalivelmente ser enganado por sua natureza. Novamente, tal como no caso das ideias claras e distintas, Descartes chega a uma mesma conclusão: ou Deus é enganador, ou a propensão incorrigível é verdadeira; como Deus não é enganador, a propensão é verdadeira.

6) Assim, portanto, sendo a causa das ideias sensiveis, concluise que os corpos existem. A conclusão, a partir dos passos apresentados, afirma que os corpos existem como causa das sensações, que as coisas

30-31), quando a luz natural corrigia a inclinação natural a crer que são os corpos que causam as ideias sensíveis, na Sexta, a luz natural já não tem razões para desautorizá-la.

${ }^{14}$ Essa regra consiste em afirmar que, se em uma percepção "inclino-me a tomá-la por verdadeira" e "não tenho nenhuma faculdade para averiguar se ela é falsa", posso ter certeza da sua verdade, em razão da incorrigibilidade (SCHIRMER, 2003, p. 86). Com efeito, Deus, meu criador, teria me dado os meios para constatar o contrário, se fosse o caso. 
materiais exteriores existem independentemente de mim. Conclui-se a prova com a afirmação desse juízo de existência.

III. Uma vez feita a exposição da prova, passo a discuti-la em função do problema central apresentado inicialmente e das questões dele decorrentes. Como foi dito, meu objetivo é analisar a prova tendo como ponto central a sua conclusão com o intuito de examinar o que ela significa e qual a sua abrangência. Em outras palavras, o núcleo da presente discussão diz respeito ao fato de que, se a prova dos corpos é uma prova de múltiplos corpos - e ela o é -, é preciso que se indiquem os fundamentos que a tornaram bem-sucedida nesse quesito e, portanto, é preciso entender de que modo a prova determina a existência de uma multiplicidade de corpos, isto é, a existência concomitante de diferentes entidades, contrariamente à alternativa (possível) de se referir a uma única.

É difícil decifrarmos as posições dos intérpretes quanto ao problema proposto e quanto à sua compreensão relativa aos resultados da prova. Em geral, eles têm dado pouca atenção à conclusão, sob o aspecto a ser aqui discutido, de sorte que praticamente não há questionamento sobre o seu significado e suas implicações. Essa ausência pode indicar, predominantemente, duas coisas: ou que a conclusão não apresente ambiguidade e que, portanto, não haja dificuldade alguma em assumirmos o seu significado literal; ou que o problema da multiplicidade seja irrelevante para a prova e esteja resolvido por um expediente distinto em outra ocasião. ${ }^{15}$

Tomemos a atitude de Gueroult como exemplo. Não há, ao longo da detalhada exposição que ele faz da prova, nenhuma discussão sobre o tema e, portanto, não há uma nítida tomada de posição. Para ele, parece

\footnotetext{
${ }^{15}$ De todo modo, a inexistência de discussão do teor da conclusão não é fácil de ser avaliada. Se a literalidade deve ser assumida, parece haver implicações que deveriam ter sido explicitadas. Se ela não pode sê-lo, como compreender a conclusão e como entender o problema da multiplicidade? Essas e outras questões parecem não ter sido respondidas pelos intérpretes.
} 
que a conclusão não apresenta dificuldades e é suficientemente clara quanto ao seu propósito. Neste caso, qual seria o significado da frase "coisas corporais existem" (AT VII, p. 80; IX, p. 63)? Na ausência de problematização, parece que o autor a compreende literalmente e, portanto, parece admitir a tese da pluralidade, a tese de que existem múltiplos corpos diferentes entre si. Entretanto, mais adiante em seu texto, Gueroult indica a separação entre a tese da existência e a tese da pluralidade quando introduz o problema da variedade geométrica dos corpos, operando, portanto, uma distinção entre a prova da existência e o momento da revelação da existência de diferenças entre as entidades existentes, ${ }^{16} \mathrm{O}$ que nos força a atribuir a ele uma compreensão distinta da que em princípio tendíamos a lhe imputar, embora o intérprete afirme todo o tempo, seguindo a letra de Descartes, que são corpos que existem, ele parece restringir a conclusão da prova à simples constatação da presença de uma entidade de natureza material sem determinação ou individuação alguma e talvez por isso o intérprete fale indistintamente de uma "prova da existência dos corpos em geral" (GUEROULT, 1953, II, p. 104) (grifos nossos). ${ }^{17}$ Uma posição mais clara nessa direção é assumida de modo explícito por Rocha ${ }^{18}$

\footnotetext{
${ }^{16}$ Assim se expressa Gueroult (1953, II, p. 104): “A prova da existência dos corpos em geral utilizou apenas o elemento formal e extrínseco do sentimento: a coação. Conforme seu método de divisão, Descartes separou no interior da ciência dois elementos do sentimento que, na realidade, são apenas um: a coação e o diverso da qualidade; e os justificou separadamente atribuindo a cada um uma função própria: à coação, a revelação da existência das coisas materiais; à diversidade das qualidades, a revelação certa da existência de diferenças nessas coisas". Essas considerações do intérprete querem mostrar, continua ele, a passagem bem-sucedida "do conhecimento da existência das coisas materiais em geral ao conhecimento, por meio dos sentidos, da existência da diversidade tanto dessas coisas como de suas propriedades" (1953, II, p. 104).

${ }^{17} \mathrm{Ou}$, então, será que Gueroult estaria entendendo como coisas distintas o que são corpos e o que é a variedade geométrica da matéria extensa? Nesse caso, ele estaria admitindo que Descartes prova primeiro a existência de corpos e depois mostra que eles são distintos entre si, separação a meu ver problemática, para não dizer inadmissível.
}

${ }^{18}$ Diz a autora: “Como vimos, a conclusão da prova do mundo externo na VI Meditação 
ao defender que a prova apresenta a simples posição da existência sem que se possa acrescentar qualquer tipo de determinação. A prova dos corpos indicaria, rigorosamente, segundo ela, tão somente a existência da matéria extensa, do mundo externo material e, assim, por meio da prova, reconheceríamos exclusivamente a existência de uma indeterminação material ${ }^{19}$ sem que nada mais se pudesse dizer sobre essa existência: as ideias sensíveis seriam indicativo da existência da matéria extensa, da sua presença ou posição, mas sem incluir aí a diferenciação dos corpos. ${ }^{20}$

Contrariamente a essas interpretações ou à falta de discussão sobre essa problemática, pretendo defender as teses apresentadas anteriormente, tendo como núcleo a de que a conclusão da prova inclui a afirmação da multiplicidade dos corpos e, portanto, é preciso lê-la literalmente e com todas as letras: são múltiplos os corpos que existem e são diferentes entre si. Além disso, a posição cartesiana, para ser legítima, exige a presença de um critério ou princípio, não um princípio (ontológico $)^{21}$ que proceda efetivamente à produção da multiplicidade dos corpos, mas aquele que permita à mente reconhecer e afirmar a distinção entre os corpos ou a individuação de cada um deles. Com efeito, como já

é a da presença de um mundo externo em geral e não a da existência determinada de coisas particulares" (ROCHA, 2000, p. 29) (grifos no original).

${ }^{19}$ Uma variação dessa "posição" seria a de considerar a indeterminação não no âmbito da existência, mas no da afirmação da existência. Nesse caso, a conclusão da prova afirmaria, de forma indeterminada e, por assim dizer, ainda desinteressada, a existência dos corpos: não uma existência indeterminada, mas uma afirmação ainda indeterminada sobre a existência, deixando para as etapas seguintes a elucidação sobre o que é essa coisa que existe. Essa variante, contudo, não melhora em nada a situação.

${ }^{20}$ Thomas Lennon (1993, p. 191-201) também defende que, na Sexta Meditação, não há, do ponto de vista metafísico, uma pluralidade de coisas materiais. Ele reconhece, entretanto, a multiplicidade do ponto de vista fenomênico.

${ }^{21}$ Os Princípios indicam ser o movimento tal princípio. Cf. Princípios, II, Art. 23 (AT VIII, p. 52-53; IX-2, p. 75). 
foi dito, não pode haver nenhuma posição de existência, em Descartes, sem algum tipo de posição relativa à determinação da entidade ou das entidades existentes.

IV. Comecemos com a análise da tese de que a multiplicidade não pode ter sido introduzida nem anteriormente nem posteriormente à prova como forma de evidenciar que ela só pode ter sido introduzida durante a prova.

Embora Descartes tenha discutido diferentes temas relativos às coisas materiais ao longo das Meditações e tenha utilizado termos relacionados à divisibilidade da matéria e à multiplicidade, em nenhum momento antes da prova da existência ocorre algum tipo de discussão sobre o problema da pluralidade e, portanto, sobre o da individuação e o da distinção entre os corpos, tendo em conta principalmente o fato de que nem sabemos se eles existem. Poder-se-ia talvez pensar que a Quinta Meditação pudesse ter feito isso, ou mesmo a Sexta Meditação antes da prova. Descartes, de fato, provou que, uma vez de posse do critério da verdade e das técnicas para evitar o erro, poderia restaurar completamente o conjunto das verdades matemáticas, as verdades relativas à extensão geométrica ou à essência das coisas materiais. E, nesse conjunto de verdades restauradas, se inclui não apenas a noção de extensão, mas também o que pode ser atribuído às suas partes como todo tipo de grandeza, figura, situação, movimento etc., bem como as particularidades que nesse âmbito se poderá encontrar. Nesse sentido, podemos pensar a res extensa abstratamente ou, então, sob certas determinações, como quando imaginamos uma parte dela atribuindo-lhe certas características particulares (figura, tamanho, etc.) correspondentes à sua delimitação territorial. É apenas nesse momento que, rigorosamente, podemos falar em $\operatorname{corpos}^{22}$ entendidos como as diferentes delimitações efetuadas na matéria extensa.

\footnotetext{
${ }^{22}$ Descartes identifica "corpo" com "parte da matéria" sem nenhuma especificação adicional. Diz ele nos Princípios, II, Art. 25: "Por um corpo, ou então por uma parte
} 
Entretanto, todas essas verdades estabelecidas na Quinta Meditação são exclusivamente geométricas e nada adiantam em relação a corpos propriamente ditos: embora verdadeiras (e reais) do ponto de vista geométrico, tais verdades são apenas possíveis no âmbito físico ou natural. A essas propriedades geométricas haverá propriedades físicas correspondentes, mas para isso é preciso provar a existência da substância material. E, portanto, embora o reconhecimento da pluralidade corporal implique o reconhecimento da existência de propriedades geométricas no mundo material (visto que a determinação ou individuação de um corpo pressupõe sua delimitação territorial, que se dá por meio da figura, da situação, do tamanho, etc.), o estabelecimento das verdades geométricas nada adianta em relação ao reconhecimento da pluralidade dos corpos existentes.

Por conseguinte, todas as verdades geométricas permanecem apenas como possíveis, no âmbito do mundo físico, antes da prova da existência, embora sejam res do ponto de vista geométrico, elas não serão fisicamente existentes e reais senão em decorrência da afirmação da existência dos corpos. Em outras palavras, a solução do problema da determinação da multiplicidade (tal como a do problema da existência) não pode ser buscada no âmbito das ideias intelectuais. ${ }^{23}$ Estas só mostram a possibilidade dos corpos e de suas propriedades geométricas; jamais a realidade física delas. As verdades claras e distintas relativas à extensão não só não podem servir como peça central à prova dos corpos, mas principalmente passam a valer para os corpos em decorrência da prova da existência deles. E isso significa que é preciso prová-los de forma independente à introdução das verdades matemáticas.

Assim, embora devamos admitir que tudo o que seja clara e distintamente percebido em relação às coisas materiais seja verdadeiro,

da matéria, entendo tudo o que é transportado em conjunto" (AT VIII, p. 53-54; IX2, p. 76).

${ }^{23}$ As ideias imaginativas tampouco nos auxiliam nisso. 
isso não significa que haja determinação do âmbito geométrico e da essência das coisas materiais para o âmbito físico e real. E, portanto, ainda que tudo o que existirá no mundo físico corresponderá a uma configuração possível da substância extensa, as verdades geométricas (fisicamente possíveis) não têm força para acarretar o que será fisicamente real ou existente. Em síntese, não há passagem do possível ao existente, embora o existente efetive uma configuração possível. Caso contrário, a própria prova poderia se basear sobre as ideias do entendimento. ${ }^{24}$

Por sua vez, não podemos aceitar que a tese da multiplicidade tenha sido introduzida depois da prova, embora Descartes, de fato, enuncia a correspondência entre variedade geométrica e variedade sensível em seguida à prova da união e, portanto, depois da prova da existência. ${ }^{25}$ Essa impossibilidade se justifica por várias razões, dentre as quais apresento as mais relevantes.

A primeira delas diz respeito ao fato de que, na hipótese de alguém questionar a tese de que Descartes se refira à multiplicidade durante a prova, parece não haver dúvida de que ele a pressupõe em seguida e, particularmente, durante a prova da união. Ora, se a multiplicidade corporal tiver sido introduzida apenas quando Descartes tratou da correspondência entre variedade geométrica e variedade sensível, não temos como entender a prova da união entre alma e corpo, entre a alma e um corpo em especial (o meu). Com efeito, a tese da união pressupõe a diferenciação entre o meu corpo, que está unido à alma, e outros ou, pelo menos um outro, exterior ao meu e distinto dele. ${ }^{26}$ Portanto, Descartes já

\footnotetext{
${ }^{24} \mathrm{~A}$ prova da distinção entre a alma e o corpo não altera esse quadro em relação à tese da multiplicidade dos corpos.

${ }^{25}$ Diz ele: "Além disso, a natureza ensina-me também que existem, ao redor do meu, vários outros corpos [...]. E, decerto, por sentir cores, sons, cheiros, calor, dureza etc., muito diversos, retamente concluo que, nos corpos de onde procedem todas essas percepções dos sentidos, há algumas variedades a elas correspondentes, embora não lhes sejam talvez semelhantes" (AT VII, p. 81; IX-1, p. 64).

${ }^{26} \mathrm{~A}$ prova, evidentemente, é da união entre alma e corpo. Ela, contudo, pressupõe a
} 
reconhece, na prova da união, a variedade geométrica ao distinguir a parte da matéria que forma meu corpo da parte da matéria que o circunda e que dele se distingue.

Em segundo lugar, se não admitirmos a pluralidade dos corpos ao longo da prova, é preciso explicar como uma entidade material única, inflexível e imóvel poderia exercer a ação requerida para a produção das sensações: nem mesmo uma única sensação seria possível. Não há como a mente ser atingida - e, portanto, se comportar passivamente frente a uma entidade ativa - no caso de a extensão se manter indivisível e homogênea, a menos que se estipule outra causa às sensações.

Em terceiro lugar, é problemático derivarmos a variedade geométrica simplesmente da variedade sensível (sensações), pois é possível, em princípio, que um mesmo corpo cause uma diversidade de ideias (sensações) ou que uma ideia tenha como origem um conjunto de causas, a menos que isso seja vetado em razão do respeito à relação causal, de natureza formal, entre ideias e corpos. ${ }^{27}$ Se tal fosse o caso, essa conclusão já estaria contida na própria prova da existência, visto que é lá que fica estabelecida a necessidade da causalidade formal. Ademais, a variedade sensível diz respeito, primeiramente, ao conteúdo da ideia - ao seu aspecto qualitativo, como diz Gueroult (1953, II, p. 104) -, que é obscuro e confuso, e envolve um entrecruzamento de diferentes ideias para diferentes configurações geométricas, algo que o conteúdo dessas ideias não pode garantir ou determinar.

Assim, a afirmação da correspondência entre variedade geométrica e variedade sensível, feita depois da prova da união, parece ter como função, não o reconhecimento ou a introdução da variedade dos corpos (sua pluralidade), mas o simples estabelecimento (e a generalização) da

distinção entre meu corpo e a matéria fora de mim, sob pena de a prova dever estabelecer a união da alma com a res extensa no seu todo. A prova da união pressupõe a distinção entre corpos, entre o meu e um outro, pelo menos.

${ }^{27}$ Parece muito oneroso, por sua vez, fundamentar esse veto simplesmente a partir de minha natureza não enganadora, por ser criação divina. 
correspondência entre duas coisas em si mesmas já estabelecidas. Com efeito, já sabemos que corpos existem (dentre os quais um é o meu) e temos consciência da diversidade de ideias sensíveis que nos advém. Sem pretender buscar estabelecer qualquer espécie de semelhança entre os dois tipos de entidades e sem pretender reconhecer a pluralidade corporal a partir da diversidade do conteúdo das sensações, a natureza ${ }^{28}$ nos ensina que podemos confiar nessa crença de que a variedade sensível denuncia a presença da variedade geométrica, dada a consciência imediata da primeira e a prova bem-sucedida da segunda. E, com isso, temos também uma razão explicativa da diversidade sensível que nos afeta.

V. A dificuldade relativa à pluralidade dos seres materiais existentes, portanto, não foi resolvida antes da prova da existência nem poderia ter sido resolvida posteriormente. Será ela, porém, uma verdadeira dificuldade? Toda afirmação de existência já não comporta o critério de determinação da entidade existente? O que ocorre nos outros juízos de existência? Há similaridades desse juízo de existência com os outros já emitidos por Descartes?

As afirmações da existência do ser pensante e de Deus não apresentam a dificuldade nos termos em que ela aparece na prova dos corpos, por tratar-se da existência de uma única entidade e não de múltiplas entidades, entretanto, eles não dispensam a necessidade de um critério ou de um processo de individuação da entidade existente, ao contrário, tais juízos incorporam ou possibilitam, no seu próprio ato de enunciação ou no processo que os produz, a individuação do ser existente.

Comecemos com a prova da existência de Deus. A identificação de um único Deus, sem a possibilidade de pensarmos em outro ou em outro ser qualquer, é muito clara e direta. Na primeira prova vemos que,

\footnotetext{
${ }^{28}$ Afirma Descartes: "Por natureza, genericamente considerada, nada mais entendo, neste momento, que Deus ele mesmo, ou a coordenação por ele instituída de todas as coisas criadas. E, por minha natureza, em particular, não entendo senão o complexo de todas as coisas que me foram atribuídas por Deus" (AT VII, p. 80; IX-1, p. 64).
} 
ao conteúdo infinito da ideia de Deus que temos, só pode corresponder o próprio ser infinito que, por definição, é único, ou seja, não é possível concebermos mais de um ser infinito. Deus, pela sua natureza, exclui qualquer outra natureza infinita e essa exclusão implica uma individuação não por oposição a outros possíveis seres infinitos, mas pela impossibilidade da existência deles. A infinitude impossibilita que tenhamos a ideia de mais de um Deus.

Por conseguinte, dado que temos a ideia de Deus, podemos demonstrar simultaneamente que Ele existe e que é único, não por exclusão, separação ou distinção, mas pela noção de totalidade e de infinito. Ele é único porque é a totalidade (em seu gênero). É por isso que Descartes pôde enunciar, um pouco antes da conclusão da primeira prova, uma definição do que seja Deus, uma definição em princípio nominal que imediatamente se torna real, dado que toda definição de infinitude é única, não pode haver diferença entre uma definição nominal e outra real, bem como entre a dimensão da infinitude da ideia e a da infinitude da coisa, ${ }^{29}$ de onde se segue a conclusão da prova. A ideia de Deus é, portanto, única e exclusiva, porque Ele é único e exclusivo: se temos a ideia de Deus - e nós a temos -, ela é de um ser infinito e único. Caso contrário, não se trata de Deus, mas de alguma criatura inventada por nossa imaginação, muito poderosa quem sabe, mas finita. Enfim, a impossibilidade da formação do infinito por composição ou pela soma de realidades finitas evidencia sua anterioridade, exclusividade e unicidade.

E, portanto, há individuação. Nesse sentido, não há possibilidade de que a relação da ideia de Deus com o ser correspondente existenteexterno e independente -, nos traga algum problema de identificação e individuação desse ser, mas é somente com o ser infinito que, nos termos aqui expostos, isso pode ocorrer. É por essa razão que o princípio de causalidade funciona de forma plena para a conclusão do argumento, uma

\footnotetext{
${ }^{29}$ Embora a realidade de uma seja apenas objetiva e a da outra seja formal. Além disso, sob outro aspecto, Deus pode ser dito causa eminente da ideia de Deus.
} 
vez que a realidade objetiva infinita de uma ideia só pode ter como causa o próprio ser infinito. O princípio de causalidade é suficiente porque é aplicado a um caso extremo (máximo) de realidade: ele nos leva a concluir pela necessidade da causa e que esta seja o ser infinito. Além disso, a infinitude implica exclusividade da causa. Ela funciona, portanto, como critério de individuação da entidade existente. Na hipótese da existência de diferentes infinitos haveria algum tipo de dificuldade na identificação de qual infinito seria a causa da ideia de infinito. Para Descartes não é o caso, visto que Deus é o único infinito e é infinito em todas as suas dimensões: um infinito com infinitos atributos infinitos.

Por sua vez, a identificação do ser pensante não se dá por impossibilidade da existência de entidades concorrentes como ocorreu com Deus. Ela tampouco pressupõe uma definição ou a determinação da natureza do existente. Mesmo assim, a afirmação da existência do ser pensante permite a sua identificação: este ser pensante sou eu.

Com efeito, não se trata de afirmar que esse ser existente sou eu por oposição aos outros eus. Ao contrário, embora Descartes venha a reconhecer a existência de outras mentes, o problema aqui inexiste. Não há discussão alguma, na Segunda Meditação, sobre a determinação do ser existente em relação às outras mentes. A identificação deste tampouco tem paralelo com o caso de Deus nem por utilização do princípio de causalidade entre realidade objetiva da ideia e realidade formal, nem por relação de qualquer gênero que seja entre exterioridade e interioridade da mente.

A determinação do ser pensante como existente se dá em função da natureza do ato de pensamento desse mesmo ser pensante. Tal ato é um ato de um ser que, simultaneamente, permite torná-lo consciente de que é sujeito desse ato. Por isso Descartes pode afirmar que eu existo e não que algum ser existe. Há uma relação causal entre ato de pensar e sujeito desse ato, uma relação causal, todavia, não entre realidade objetiva e realidade formal, mas entre duas realidades formais. ${ }^{30}$ Não é isso, porém,

${ }^{30}$ Talvez, mesmo assim, mediatizada pela realidade objetiva. 
que possibilita a identificação imediata (por nós) do ser existente: caso contrário, toda relação causal existente no mundo denunciaria a causa por si mesma a nós. A identificação do ser pensante existente - e, portanto, a individuação que aí ocorre - se dá pela duplicidade presente na relação entre ato de pensar e sujeito do ato, o que significará a introdução da noção de consciência. Todo ato de pensar é um ato de pensar de um sujeito consciente desse ato: no caso em questão, o sujeito se dá conta de que, quando duvida (um modo de pensar), tem consciência imediata de que é ele mesmo que exerce o ato de duvidar. Há uma única ação com uma dupla direção: entre ato e sujeito do ato; entre ato e consciência do sujeito do ato. O sujeito exerce um ato de pensamento e sabe que esse ato é necessariamente seu.

Em outras palavras, a noção de consciência de si, presente no primeiro juízo de existência, permite a identificação desse ser existente. Como todo ato de pensamento torna o sujeito desse ato imediatamente consciente de seu ato, é impossível dissociar o ato de pensamento (consciência) da consciência do ato. ${ }^{31} \mathrm{E}$, portanto, dada essa identificação, não é preciso um critério adicional de individuação do sujeito pensante: este só pode ser eu. Além disso, essa identificação ocorreu sem que eu tivesse necessidade de determinar a natureza do ser pensante. Não foi a partir da estipulação ou da definição da natureza do ser pensante que determinei a existência dele, isso só é possível para o caso de Deus. Nem por isso esse juízo de existência dispensou a existência de um critério: a consciência de que o ato do sujeito pensante é um ato de pensar meu. $\mathrm{O}$ juízo que determina a existência da res cogitans também pressupõe um princípio de individuação da entidade existente.

\footnotetext{
${ }^{31}$ Cf. Landim Filho (1997, p. 48). "Como todo ato supõe o sujeito do ato, todo ato de consciência supõe o sujeito de consciência. Mas ser sujeito do ato de consciência significa ser consciente e, por sua vez, ser consciente significa ser consciente de ser sujeito de seu ato de consciência. Portanto, quem efetua um ato de consciência 'sabe' que é sujeito deste ato, pois é impossível realizar um ato de consciência sem ter consciência de ser sujeito do ato".
} 
$\mathrm{E}$, assim, pelo que sugerem os dois casos apresentados, todo juízo de existência pressupõe uma forma pela qual se dê a individuação das entidades que serão provadas como existentes. Como vimos acima para o do ser pensante e de Deus, tratar de uma existência é tratar de uma entidade que se individualiza e se determina de alguma forma, mesmo que não se trate de uma determinação por limitação ou por contraposição a outra entidade. A delimitação não é necessariamente por limitação (ou por distinção entre indivíduos de uma mesma espécie), mesmo para uma entidade finita como o ser pensante, de maneira que pode variar, mas não pode faltar, o modo de determinação de cada uma.

No caso dos corpos, entretanto, a necessidade da presença de um critério de determinação das entidades existentes é ainda mais premente do que nos outros casos, e o é, primeiramente, pelo fato de haver separação, no interior da prova, entre a constatação da existência e a determinação das entidades existentes. Com efeito, no segundo passo da prova já está assegurada a existência da entidade causadora das sensações, embora permaneça totalmente indeterminada: existe uma faculdade ativa responsável pela ação exercida sobre a minha mente, por meio da qual são produzidas as ideias sensíveis; tal faculdade reside em uma entidade existente fora da mente e independente desta. Dada a consciência imediata e, portanto, a certeza de nossa capacidade passiva de sentir, está assegurada a existência da entidade em que reside a sua correspondente faculdade ativa. Logo, está assegurada sua existência, embora sua identidade permaneça desconhecida, cabendo às etapas posteriores apontá-la.

Em segundo lugar, é preciso ter em conta que, quando Descartes aponta na terceira etapa da prova, o corpo como entidade candidata a ser o correspondente causal das ideias sensíveis, embora tenhamos uma ideia clara e distinta do que seja um corpo (do ponto de vista geométrico), parece que não podemos introduzi-la automaticamente no âmbito da prova. Descartes nomeia os corpos como causas formais das ideias e tudo o que podemos saber sobre essas causas é o que poderá ser indicado por tais 
ideias. Aqui também devemos ir das ideias às suas causas e, portanto, só podemos afirmar algo da causa a partir do que é denunciado pela ideia, sob pena de estipularmos a identidade da causa independentemente do que revela o efeito. Assim, corpos, por ora, são entidades desconhecidas, cuja identidade corresponde rigorosamente ao mínimo exigido pela relação causal estabelecida (por ser de natureza formal e não eminente). ${ }^{32}$

A terceira razão da necessidade da presença de um critério para a determinação da multiplicidade dos corpos é o fato de que uma prova de existência deve determinar minimamente a entidade existente e, portanto, determinar também se a existência diz respeito a apenas uma única ou a múltiplas entidades. Como todo juízo de existência deve possibilitar a determinação de pelo menos uma entidade existente. É preciso esclarecer, no caso dos corpos, as razões pelas quais a prova não se restringe a esse mínimo e determina a pluralidade deles. ${ }^{33}$

VI. Examinadas tais questões, devemos nos voltar novamente às etapas da prova e à análise das ideias sensíveis, que são seu objeto central. O que tais ideias indicam ou denunciam? Como são obscuras e confusas, o que poderiam indicar? A resposta imediata é que, sendo materialmente falsas, nada representam. E, embora sem capacidade representativa, elas denunciem ao sujeito pensante a consciência de uma receptividade, de

\footnotetext{
${ }^{32} \mathrm{Em}$ outras palavras, quando Descartes nomeia, na terceira etapa da prova, os corpos como causas possíveis das ideias sensíveis, em cujo caso eles seriam causas formais (e não eminentes), rigorosamente falando, essa entidade intitulada "corpo" nos é ainda desconhecida: a entidade corpo é uma entidade $x$, ainda indeterminada, que corresponderá ao mínimo exigido pelo seu efeito (por ser a causalidade de natureza formal). Portanto, o que a causa será vai depender do que for requerido pelo efeito, visto que poderemos atribuir a ela apenas o mínimo necessário ao poder causal.

${ }^{33}$ Dito de outro modo, o que se espera de todo juízo de existência bem-sucedido é que ele aponte a existência de uma entidade necessariamente. Nesse caso, o problema da determinação da entidade passa quase que despercebido. É diferente o caso de um juízo que aponta a existência de múltiplas entidades, por exceder o mínimo requerido.
} 
uma presença. Esta não seria a presença de uma entidade, de uma individualidade? Além disso, essa entidade deve possuir uma faculdade ativa, responsável pela coação exercida sobre a mente. Essa faculdade ativa não pressupõe uma entidade determinada? As ideias sensíveis não são, enfim, elas mesmas entidades, isto é, unidades, que exigem unidades correspondentes, na medida em que acusam a existência de algo exterior?

As ideias sensíveis, da mesma forma que todas as outras, são produzidas pela substância pensante: é o ser pensante que as causa, sob o ponto de vista da sua realidade formal. Sob esse aspecto, elas nada denunciam para além do sujeito e, como tais, são claras e distintas.

Sob o aspecto de seu conteúdo, por outro lado, o problema é que elas são consideradas materialmente falsas. ${ }^{34}$ Embora sendo consideradas representações em alguma medida, ${ }^{35}$ não são representações de coisas, não discriminam seus conteúdos como objetos. Se representar é tornar presente algo à consciência, é apresentar a ela uma coisa ou entidade, as ideias sensíveis não cumprem essa função, mesmo que visem, de um modo obscuro e confuso, algo heterogêneo e exterior ao pensamento. Ainda que envolvam uma referência ao corpo como uma de suas condições, o seu conteúdo não permite que concluamos algo sobre a determinação dessa condição.

Entretanto, quando analisamos as etapas da prova, percebemos que seus dois primeiros passos já determinam a existência de uma entidade

\footnotetext{
${ }^{34}$ Diz a Terceira Meditação: “há, porém, nas idéias, uma certa outra falsidade material, quando elas representam uma não-coisa como se coisa fosse" (AT VII, p. 43; IX-1, p. 34). Por sua vez, as Quartas Respostas afirmam que tais ideias "não representam nada de real" (AT VII, p. 234; IX-1, p. 181).

${ }^{35}$ Os conteúdos das ideias sensíveis são as próprias sensações ou estados subjetivos, e não objetos representados por elas. Mesmo assim, considerados como algo análogo à realidade objetiva das ideias representativas, ao indicarem alguma coisa de heterogêneo e exterior ao pensamento, podem ser denominadas ideias. Para uma análise das ideias materialmente falsas, cf. o capítulo IV de Landim Filho (1992, p. 81-97).
} 
causadora das sensações. As noções de passividade ${ }^{36}$ e de coação indicam uma relação de dependência a uma entidade exterior, que, embora desconhecida, é uma res e, como tal, tem um mínimo de determinação. Passividade e coação indicam uma relação de dependência a uma condição heterogênea ao pensamento, o que significa dizer que a coação é sinal da presença de uma entidade externa e da sua manifestação à mente: toda ideia sensível denuncia a presença de uma res externa e a denuncia como sua causa. A primeira conclusão que podemos tirar é, portanto, que existe uma substância que possui a capacidade de produzir as ideias sensíveis em nós. Esse poder é detectado por meio da coação que a mente sofre diante da presença dessa entidade ou dos seus efeitos.

Além disso, a relação causal aplicada à coação exercida sobre a mente exige um mínimo de determinação da entidade que exerce a atividade. A relação causal não exige a determinação do que seja a entidade, mas exige que ela seja uma entidade, uma coisa. Embora a ideia sensível em si, enquanto entidade mental, não exija nada extramental - e tampouco seu conteúdo o exija, dado que sua realidade objetiva é praticamente nula -, a coação causal parece exigi-lo. A relação causal em questão não é uma relação causal que exija semelhança entre causa e efeito, mas exige a presença e o efetivo exercício de um poder sobre a passividade da mente. ${ }^{37}$ É uma entidade que se denuncia por sua

\footnotetext{
${ }^{36}$ Embora o apelo à relação entre atividade e passividade não suponha a existência de faculdade ativa, a ocorrência (ou uso) da relação o exige.

${ }^{37}$ A ideia de vazio poderia invalidar essa tese. Essa ideia ilusória, contudo, se constitui não pela inexistência de coação externa, mas por descontinuidade entre diferentes coações e pela interpretação que a mente faz desse intervalo: aí não há corpos, conclui a mente, porque, se houvesse, eles estariam me coagindo a ter consciência deles. A ideia de vazio, portanto, não se configura como exceção. Ao contrário, reforça a tese, uma vez que mostra que a simples existência de corpos não é suficiente para causar a coação, mas é preciso que eles exerçam certa atividade sobre nosso sistema perceptivo. Em outras palavras, o ar que me rodeia, quando estático, não se denuncia a mim, exatamente porque não se diferencia suficientemente de mim, cujas partículas permanecem tão unidas às de meu corpo que penso nada existir ao meu redor.
} 
"faculdade ativa" e se denuncia como existente. ${ }^{38}$

Senão vejamos sob outro ponto de vista. O que dá identidade a cada uma das ideias sensíveis? O que permite distingui-las umas das outras? Não é do ponto de vista da sua realidade formal (isto é, da sua matéria) ${ }^{39}$ que elas se distinguem, visto que todas são modos de pensar. Materialmente, portanto, são todas iguais, feitas da mesma matéria indeterminada fornecida pelo espírito. ${ }^{40}$ Por outro lado, cada uma tem uma identidade própria e, sob esse aspecto, as ideias se distinguem entre si pela forma ${ }^{41}$ própria de cada uma e, como tal, cada uma tem uma unidade e uma identidade que lhes permite identificação e distinção entre si. No caso das ideias claras e distintas, a realidade objetiva é que dá essa identidade a elas; no caso das ideias sensíveis, obscuras e confusas, o que dá identidade e forma a cada

\footnotetext{
${ }^{38}$ Alguém poderia ir mais além e sugerir o seguinte raciocínio. As ideias sensíveis são materialmente falsas porque pretendem representar entidades quiméricas (non res) como coisas (res). Entretanto, entidades quiméricas não seriam ainda assim entidades? Sob o ponto de vista do conteúdo, evidentemente que não, contudo, sob o ponto de vista da mera manifestação de algo à mente (ponto de vista formal), há um conjunto mínimo de fatores que mesmo a quimera deve satisfazer: ela precisa se manifestar como ilusão e, como tal, embora ilusória (conteúdo), preenche os requisitos formais do aparecer à consciência. É por isso que, do ponto de vista da consciência, não há distinção entre ideias verdadeiras e falsas, todas elas indubitáveis enquanto modos de pensamento.

${ }^{39}$ Diz Descartes nas Quartas Respostas: "se as considerássemos [as ideias], não enquanto representam uma coisa ou outra, mas somente como sendo operações do entendimento, poderíamos verdadeiramente dizer que elas estariam sendo tomadas materialmente" (AT IX-1, p. 180).

${ }^{40}$ Como toda ideia, as ideias sensíveis são pensamentos e, como tais, são produzidas pelo ser pensante e constituídas pela mesma matéria de que ele é constituído. Diz Descartes na Carta ao P. Mesland, de 2 de maio de 1644: "Eu não coloco outra diferença entre a alma e suas ideias senão como as que há entre um pedaço de cera e as diversas figuras que ele pode receber". (AT IV, p. 113).

${ }^{41}$ Voltemos ao texto das Quartas Respostas: "visto que as ideias mesmas nada mais são senão formas, e visto que não são compostas de matéria, todas as vezes em que são caracterizadas enquanto representam alguma coisa, elas não são tomadas materialmente, mas formalmente" (AT IX-1, p. 180; grifos no original).
} 
uma delas é a identidade distinta de cada uma das coações sofridas. Se há ideias sensíveis distintas é porque a mente se submete a situações de passividade e de receptividade distintas e, portanto, a coações distintas, em razão dos modos distintos pelos quais a causa se presentifica.

Isso, porém, não implica, ainda, a existência de múltiplas causas, mas apenas a existência de manifestações distintas à mente. A existência de múltiplas ideias sensíveis não exige a existência de múltiplas causas, visto que uma única entidade poderia, em princípio, causar a todas: uma única causa poderia se apresentar com poderes diferenciados e manifestarse distintamente em cada nova ideia.

Entretanto, se isso vier a ocorrer, tratar-se-á de uma relação causal de natureza eminente, possibilidade excluída pelas etapas seguintes, quando Descartes elege que a relação causal entre ideia e corpo é de natureza formal. Ora, o que significa afirmar que algo seja uma causa e que seja uma causa formal? Se a causa é formal, isso significa que ela não pode ser mais "sublime" que o efeito; se ela é causa, isso significa que ela produz o efeito e, para tal, deva ser, pelo menos, tão "sublime" quanto o efeito produzido. E, portanto, se os corpos são causas formais das ideias sensíveis, eles não podem ter nem mais nem menos graus de realidade do que os requeridos pelos seus efeitos. Se tiverem mais, serão causas eminentes, se tiverem menos, não terão poder causal.

Nesse sentido, os elementos que dão configuração e forma a todas as ideias sensíveis, embora se apresentem como carentes de conteúdo, mesmo assim, garantem a cada uma delas unidade e identidade e, portanto, garantem a distinção entre elas, logo, toda ideia sensível, por ser minimamente determinada ou delimitada, exigirá o mesmo da causa formal. É esse elemento formal da ideia, ${ }^{42}$ sem determinação de conteúdo, que

\footnotetext{
${ }^{42}$ Os vários sentidos do termo "forma" podem causar confusão. Há três sentidos distintos aqui: 1) a causa formal se opõe à causa eminente, a primeira se restringindo à realidade exigida pelo efeito, a segunda extrapolando a "igualdade" entre causa e efeito; 2) a realidade formal se opõe à realidade objetiva, esta só existindo no âmbito das ideias (seu conteúdo), enquanto a primeira se refere a tudo o que existe; 3) a
} 
parece exigir algum tipo de determinação mínima da entidade que causa o constrangimento àmente e lhe permite circunstanciá-lo, determiná-lo, enfim, detectá-lo. Como seria possível detectar a coação sem determinação alguma? Por conseguinte, não se exigirá essa determinação mínima da sua causa formal? Tal como "a cera recebe a figura impressa por um selo" (AT X, p. 412), o corpo deixa a marca de sua existência na mente, "imprimindo" minimamente esse elemento formal de determinação nas ideias sensíveis.

E, portanto, se uma ideia clara e distinta, pelo seu conteúdo, exige uma entidade correspondente, a coação e a relação causal não podem deixar de exigir, analogamente, a presença e a determinação da entidade correspondente. A coação causal nas ideias sensíveis (obscuras e confusas) parece ser o correspondente da realidade objetiva das ideais claras e distintas. Além disso, em se tratando de juízos de existência, a determinação da entidade correspondente deve ser precisa, em razão de sua função referencial: cada ideia precisa funcionar como signo de existência da entidade-causa. No caso dos corpos, o juízo de existência tem apenas função referencial, cujo êxito exige a determinação da entidade correspondente como unidade ou como coisa. É enquanto signos da existência das coisas corporais que as ideias determinam o sentido e os limites da natureza formal da causa correspondente.

Caso seja aceitável esse ponto de vista, parece não ser necessário apelar para o horizonte da qualidade e do conteúdo das ideias sensíveis para derivarmos a variedade geométrica dos corpos. Há uma diferença irredutível, de natureza formal, entre as ideias, eessa diferença aponta para as diferentes coações sofridas pela mente, cada uma delas exigindo uma causa de natureza formal e, portanto, distintas entre si. E, assim, cada ideia seria signo da existência de uma entidade, teria uma função referencial própria.

forma se opõe à matéria e é o que dá os contornos a algo como algo determinado. No caso das ideias sensíveis, a forma distinta de cada uma delas, não podendo provir de algum expediente ligado ao seu conteúdo (à sua realidade objetiva), em razão da sua falsidade material, provém das diferentes coações que estão na sua origem. 
Cada ideia sensível, por si, indicaria a existência de uma determinada entidade como sua causa. Para cada nova ideia, por ser uma nova ideiae, portanto, por implicar uma nova faculdade ativa atingindo a mente de onde emergiria uma nova coação de origem externa - deve ter uma causa formal diferente. A natureza causal de cada ideia e a individuação das diferentes coações exercidas sobre a mente indicariam a existência de diferentes entidades (com natureza indeterminada, mas todas elas do mesmo gênero). E, assim, a pluralidade das ideias sensíveis erigiria imediatamente uma pluralidade de coisas materiais, visto que as diferentes impressões sensíveis que chegam à mente não podem ser atribuídas à mesma causa sob pena de não se tratar mais de causas formais.

Em síntese, podemos indicar três etapas principais por meio das quais os corpos são reconhecidos como entidades múltiplas existentes.

A primeira se dá no âmbito da coação. A coação causal exige uma entidade existente como causa. Dizer que há algo externo que exerça uma ação sobre a mente é reconhecer uma entidade externa desconhecida, mas, ainda assim, uma entidade que tenha poderes para tal. O mínimo que se deva reconhecer na causa é certa unidade que lhe garanta o status de entidade e o poder de coação. Uma causa exige isto: ter o poder de causar, estando esse poder nela mesma. A aplicação da relação causal explicita uma diferenciação entre causa e efeito e uma individuação da causa e do efeito.

A segunda etapa se dá no âmbito da causalidade formal. Se há uma causalidade de natureza formal (e não eminente), as diferentes ideias sensíveis (que implicam diferentes coações e diferentes relações causais) denunciam diferentes causas. Embora diferentes causas talvez pudessem produzir as mesmas impressões na mente, as diferentes impressões sensíveis que chegam à mente (as diferentes ideias) não podem ser atribuídas à mesma causa sob pena de não se tratar mais de causas formais. ${ }^{43}$

\footnotetext{
${ }^{43}$ A pluralidade das ideias sensíveis exige imediatamente uma pluralidade de corpos. O cérebro só pode comunicar à mente distintas impressões sensíveis, se houver distintas formas de disposição de uma parte dele (da glândula pineal) - o que
} 
Por fim, a inclinação natural e incorrigível coroa com êxito essa trajetória. E é somente com essa inclinação incorrigível - e incorrigível porque nosso Deus não nos deu meios para corrigi-la ${ }^{44}$ - que podemos ter certeza de que essas entidades determinadas, determinadas apenas enquanto entidades diferentes entre si e correspondentes causais formais às ideias, são o que chamamos de corpos. Eles, portanto, existem e existem como pluralidade. ${ }^{45} \mathrm{~A}$ inclinação irresistível nos garante a natureza formal da causa: ela não determina nenhum conteúdo referente a essas entidades existentes, em razão do fato de ser uma propensão irracional que, como tal, não se deixa analisar quanto ao seu conteúdo. A veracidade divina, por sua vez, não nos tendo dado meios para que possamos duvidar de uma percepção nem meios de prevenir, evitar ou corrigir o erro de julgála como verdadeira, dá cobertura à crença nessa percepção, devendo ser ela indubitavelmente verdadeira: a veracidade divina deve cobrir apenas as percepções e crenças em relação às quais não temos escolha, a não ser ou tomá-las por verdadeiras, ou tomar Deus por enganador. E, como Ele não é enganador, esse juízo de existência "corpos existem" é verdadeiro.

significa uma divisão efetiva da matéria que o compõe, pois "toda vez que esta se acha disposta do mesmo modo, mostra à mente uma mesma coisa" (AT VII, p. 86; IX-1, p. 69).

${ }^{44}$ Com isso, nossa inclinação a crer que são os corpos a causa das sensações recebe uma delimitação precisa. Nossa natureza indica irresistivelmente, com o aval divino, qual o conteúdo da entidade que é causa, uma vez que formalmente já está determinada: ela é uma entidade que corresponde formalmente ao seu efeito. E é somente nesse momento, em que forma e conteúdo se juntam, que posso denominar a causa com o seu devido nome: corpo.

${ }^{45}$ Por isso, Descartes pôde afirmar que é clara e distinta a percepção de que as ideias sensíveis nos remetem a algo exterior, independente e diferente da mente. Diz ele na Carta ao Hyperaspistes, de agosto de 1641: "eu não provei a existência das coisas materiais do fato das suas ideias estarem em nós, mas do fato que elas se apresentam a nós de tal sorte que nós conhecemos claramente que elas não são feitas por nós, mas que elas nos vêm de alhures" (AT III, p. 428-429; Alquié II, p. 367) (grifos nossos). Na verdade, a prova como um todo é clara e distinta: embora apele a uma propensão obscura e confusa, não é uma prova obscura e confusa. 
VII. E, assim, não é aleatória ou desinteressada a ocorrência do termo "corpos" (no plural) no interior da prova. Além disso, ela reitera a tese de que a entidade corpo só pode existir em multiplicidade dada a forma necessariamente solidária de sua existência. Finalmente, poder-seá compreender o modo pelo qual a res extensa pode se manifestar à mente, em razão da necessidade da presença de uma faculdade ativa por meio da qual os corpos possam atingir a passividade da consciência sensível.

Não há um paralelismo completo entre as ontologias do mundo espiritual finito e do mundo material ou físico. Para Descartes, é verdade, há também uma multiplicidade de mentes, mas elas são independentes entre si e, portanto, são substâncias no sentido mais completo da palavra (dentro da aplicação que concerne aos entes finitos). Assim, cada ser pensante é em si uma substância, tendo seus próprios modos, embora partilhe com as outras mentes o que é essencial a toda substância pensante. Por essa razão, a existência de uma substância pensante em especial (eu) se deu independentemente da suposição da existência de outras mentes: uma substância pensante em nada depende de outra substância pensante (finita), a começar pela posição de existência que, anterior a qualquer outra, é uma autoposição de existência.

A perspectiva do mundo material é distinta, embora talvez até se possa chamar de substância cada um dos corpos (uma tese problemática); ${ }^{46}$ o que é certo é que a res extensa em sua totalidade o é. Os corpos, substâncias ou partes ${ }^{47}$ dela (pouco importa), serão recortes dessa mesma e única substância. Corpos só existem porque há um princípio, uma

\footnotetext{
${ }^{46} \mathrm{~A}$ defesa dessa tese encontra apoio em textos de Descartes, tais como a Carta a Gibieuf, de 19 de janeiro de 1642 (AT III, p. 477) e os Principios, II, Art. 55 (AT VII, p. 71; IX-2, p. 94). Discussões sobre o tema se encontram, por exemplo, em Garber (1992, p. 175-177) e em Rodis-Lewis (1971, p. 383-384; p. 548, n. 60).

${ }^{47}$ Dizer que o corpo é um modo também é problemático, pois as partes de uma substância não são modos. Diz Descartes nas Sextas Respostas: "o corpo é uma substância cujo modo não pode ser parte" (AT IX, p. 234).
} 
"faculdade ativa", que opera o recorte da homogênea, eterna e indiferenciada res extensa.$^{48}$ Um corpo não se origina senão por diferenciação de uma parte da matéria em relação a outra parte. Nesse sentido, um corpo só emerge por oposição a outro corpo. Não se pode falar de um corpo existente sem que se admita concomitantemente pelo menos mais um, a menos que estejamos utilizando a palavra "corpo" como sinônimo de extensão ilimitada e indefinida. Um corpo, portanto, é uma delimitada parte da extensão, logo emerge, concomitantemente, a um outro corpo que é exterior à parte delimitada. Os corpos não se individualizam por si mesmos, mas pela oposição a outros. Enquanto existem diferentes mentes independentes entre si e indiferentes umas às outras, eles só podem existir em dependência entre si e por diferenciação. Assim, falar em corpo existente é falar em corpos, é falar em corpos no plural.

Parece-me também que, em Descartes, não há existências indeterminadas. Caso existissem, não poderíamos detectá-las: uma entidade indeterminada, caso existisse, não poderia presenciar-se à mente. Como vimos acima para o caso do ser pensante e para o caso de Deus, tratar de uma existência é tratar de uma entidade que se individualiza e se determina de alguma forma, mesmo que não se trate de uma determinação por limitação ou distinção entre indivíduos de uma mesma espécie. No caso dos corpos, a individuação se dá por contraposição aos outros corpos. Eles se delimitam reciprocamente e é pela sua diferença de comportamento que emergem as sensações ou ideias sensíveis. ${ }^{49}$

${ }^{48}$ Daqui parece que podemos extrair a presença (necessária?) do movimento.

${ }^{49}$ Embora não seja a ocasião de descrevermos as etapas envolvidas na formação de uma sensação, talvez valha a pena lembrar os exemplos dados por Descartes no Mundo a respeito do ar que nos cerca, do calor do coração, do peso de nosso corpo, etc., os quais não podem ser percebidos: "E a razão disso é bastante clara, pois é certo que não podemos sentir nenhum corpo a menos que ele seja a causa de alguma alteração nos órgãos de nossos sentidos, isto é, a menos que ele mova de alguma maneira as pequenas partes da matéria de que tais órgãos são compostos. Podem perfeitamente fazê-lo os objetos que não se apresentam sempre. [...] Mas, quanto aos que nos tocam continuamente, $[. .$.$] não podem de maneira nenhuma ser$ 
VIII. A prova da existência dos corpos - se bem sucedida no

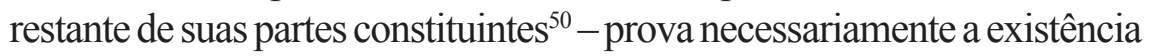
dos corpos em sua multiplicidade e diversidade: "as coisas corporais existem", diz Descartes, e nós devemos levá-lo a sério. Tal como os outros juízos de existência, o juízo de existência das coisas materiais exige a determinação mínima da entidade referenciada por ele.

A determinação ocorre em cada um desses juízos a seu modo, mas não pode faltar. No caso de Deus, ela se dá ao redor da noção de infinito; no caso do ser pensante, ela se dá ao redor da noção de consciência. No caso dos corpos, pretendi demonstrar que ela se dá ao redor do aspecto formal (e não qualitativo) da coação causal.

A diferença fundamental entre os tipos de juízos de existência ocorre em razão da diferença das regiões ontológicas respectivas a cada um. O ser infinito é único pela sua própria infinitude. O princípio de causalidade possibilita determinar a existência dessa entidade ao mesmo tempo infinita e única. O ser pensante se põe como existente, desconsiderando o problema das outras mentes. Não que elas não existam ou não possam existir, simplesmente não vem ao caso saber disso para a "prova" de sua existência. Ele sabe que é ele que existe, porque o ato que põe a existência determina que essa existência é necessariamente a dele mesmo. Os corpos, por outro lado, só existem na sua interdependência como configurações parciais ou delimitações da substância extensa. Por isso, diferentemente dos outros seres existentes, eles só existem em pluralidade, solidariamente e só podem ser detectados como tais. Não haveria, portanto, como provar a existência da entidade material, externa

sentidos" (AT XI, p. 21-22). Em outras palavras, Descartes reconhece aqui que um corpo que não se diferencia do meu não pode ser detectado por mim e, portanto, não pode estar na origem de uma sensação: as sensações têm sua origem na diferenciação entre os corpos, a começar pela distinção entre o meu e os demais.

${ }^{50}$ Para um exame exaustivo e completo da prova, dever-se-ia tratar detalhadamente de outros temas, como, por exemplo, o que diz respeito à impossibilidade de o princípio ativo se localizar no sujeito e o de que Deus seria enganador se as ideias sensíveis não fossem causadas pelos corpos. 
e independente da mente, sem simultaneamente haver determinação dela como diversidade (que se dá pela sua efetiva divisibilidade ou separação, os corpos). Embora diferente dos demais juízos, há aqui, no juízo de existência dos corpos, também necessidade desse expediente de determinação das entidades existentes, desta vez da multiplicidade deles.

\section{REFERÊNCIAS}

ALQUIÉ, Ferdinand (Ed.). Euvres philosophiques de Descartes. Paris: Classiques Garnier, 1988-89. 3 v.

DESCARTES, René. Discurso do método; Meditações; Objeções e respostas; As paixões da alma; Cartas. 3. ed. São Paulo: Abril Cultural, 1983. (Os Pensadores).

. Meditações sobre filosofia primeira. Edição em latim e em português. Tradução de Fausto Castilho. Campinas: Editora da Unicamp, 2004.

. Euvres de Descartes. Publiées par Charles Adam et Paul Tannery (AT). Paris: Vrin, $1996.11 \mathrm{v}$.

. O mundo ou Tratado da luz; O homem. Apresentação, tradução e notas: César Augusto Battisti e Marisa Carneiro de Oliveira Franco. Campinas: Editora da Unicamp, 2009.

GARBER, Daniel. Descartes' metaphysical physics. Chicago: The University of Chicago Press, 1992.

GUEROULT, Martial. Descartes selon l'ordre des raisons. Paris: Aubier-Éditions Montaigne, 1953.v. 2.

LANDIM FILHO, Raul. Evidência e verdade no sistema cartesiano. São Paulo: Loyola, 1992.

. Idealismo ou realismo na filosofia primeira de Descartes: análise da crítica de Kant a Descartes no IV Paralogismo da $C R P[\mathrm{~A}]$. In: Analytica, 1997, v. 2, n. 2, p.129-159. 
LENNON, Thomas M. The battle of the gods and giants: the legacies of Descartes and Gassendi, 1655-1715. Princeton: Princeton University Press, 1993.

ROCHA, Ethel Menezes. Princípio de causalidade, existência de Deus e existência de coisas externas. In: Cadernos de história e filosofia da ciência, jan./jun., 2000, v. 10, n. 1. p. 7-30.

RODIS-LEWIS, Geneviève. L'œuvres de Descartes. Paris: Vrin, 1971. v. 2.

SCHIRMER, César. A afirmação da existência dos corpos nas Meditações de Descartes: verdade e propensões incorrigíveis. 2003. Dissertação de Mestrado - Programa de Pós-Graduação em Filosofia, Universidade Federal Do Rio Grande do Sul. Porto Alegre, 2003.

Data de registro: $18 / 07 / 2011$ Data de aceite: $24 / 08 / 2011$ 